\title{
Blood donation practice and associated factors among health professionals in Tigray regional state public hospitals, northern Ethiopia
}

Tsige Tadesse ${ }^{1}$, Tadis Berhane ${ }^{2}$, Teklehaymanot Huluf Abraha² ${ }^{2}$ Berihu Gidey ${ }^{3}$, Elsa Hagos ${ }^{4}$, Teklit Grum² and Hadgu Gerensea ${ }^{5^{*}}$

\begin{abstract}
Objective: The demand for blood and blood products are increasing in all part of the globe, especially in the developing nations. However, there is limited information on the level of blood donation practice and their related factors. Therefore, assessing the level of blood donation practice and its determinant factors among health professionals have a paramount importance in designing an effective strategy for sustaining adequate and safe blood provision in the hospitals.

Results: Out of 556 health professionals, 266 (47.8\%) had ever donated blood in their life time. Age above 30 years $(\mathrm{AOR}=2.75695 \% \mathrm{Cl} 1.055-7.197)$, married health professionals ( $\mathrm{AOR}=1.72995 \% \mathrm{Cl} 1.091-2.739$ ), health professionals' knowledge of blood donation (AOR $=3.40395 \% \mathrm{Cl} 2.296-5.044$ ), health professionals' attitude towards blood donation ( $\mathrm{AOR}=3.4195 \% \mathrm{Cl} 2.320-5.041$ ) and health professionals who attend degree education ( $\mathrm{AOR}=0.31595 \%$ $\mathrm{Cl}$ 0.104-0.950) were significantly associated with blood donation behavior of health professionals. The magnitude of blood donation practice was found low. Therefore, the Ethiopian Red Cross Society and ministry of health should continue increasing the attitude and knowledge of health professionals toward blood donation practices are the key avenues interventions.
\end{abstract}

Keywords: Attitude, Blood donation

\section{Introduction}

Contemporary blood transfusion is an extremely desirable component of health care delivery system. Each year millions of lives are saved through safe blood transfusion. The demand for blood and blood products are increasing in all part of the globe [1-4].

Practice towards blood donation among health professional varies in Sub-Saharan Countries, which is, 22.1\% in Nigeria [5], 32.2-38.3\% in Ethiopia [6-8]. As research evidence show that; gender, age, marital status, department, work experiences significantly associated with

\footnotetext{
*Correspondence: hadgugerensea2016@gmail.com

${ }^{5}$ Department of Neonatal Nursing, School of Nursing, College of Health

Sciences, Aksum University, Po.Box 298, Aksum, Ethiopia

Full list of author information is available at the end of the article
}

Knowledge, attitude and practice [6, 8, 9]. knowledge of the of health professionals about blood donation, the presences of family members or relatives who received blood are also the key predictors for practice toward blood donation among health professionals $[2,6]$. Similarly, health professionals' attitude towards blood donation was significantly and independently associated with blood donation behavior of health professionals [6].

In Ethiopia, blood services have been mainly provided by Ethiopian Red Cross Society (ERCS) since 1969. The main objective of then one profit society is blood bank and transfusion services include collection, processing, storage and provide human blood intended for transfusion. Blood from ERCS covered only for the need of $52 \%$ of national hospitals in the country [10-14]. 
Health professionals are expected to have adequate knowledge, attitude and should practiced voluntary blood donation in order to filled the scarcity of blood availability in the health facilities. However, the level of practice among the health professionals to ward blood donation is poorly assessed in the study area. Therefore, assessing the level of practice towards blood donation and its determinants factors among health professionals have a paramount in designing an effective strategy for sustaining adequate and safe blood provision in the hospitals.

\section{Main text \\ Methods \\ Study design, period and setting}

The study was conducted in Public Hospitals of Central, North West and Western zone of Tigray. Tigray is one region of Ethiopia which covers an area of $109 \mathrm{~km}^{2}$ and its elevation is 2084 M above sea level [15-25]. Institutional based cross-sectional study was conducted to assess the knowledge, attitude, and practice towards blood donation and its associated factors among health professionals in Public Hospitals of Central, North West and Western zone of Tigray from August to September 2016.

\section{Source and study population}

All health professionals who are working in the selected general hospitals in the three zone of Tigray Regional State were the source population. The study populations were randomly selected health professionals who were employees of the selected public hospitals during the data collection time.

\section{Sample size determination}

The sample size was determined using a single population proportion formula by taking the prevalence rate of practice (32.6\%) from Addis Ababa study [11], which gives the largest sample size. Using 95\% CI and 5\% margin of error, the sample size was found to be 556 after considering $10 \%$ non-response rate and design effect of 1.5 .

\section{Sampling techniques}

A multi-stage sampling technique was used to recruit the study participants. At first stage, five general hospitals were selected from total of seven general hospitals in the 3 zones by lottery method. At second stage, random sampling technique was used to select health professionals from human resource list registration as a sampling frame with proportional allocation to the size of each general hospital.

\section{Data collection}

Data were collected by using a structured and pretested self-administered questionnaire.

\section{Operational definitions}

Based on the mean score, those who score mean and above for knowledge questions were categorized as knowledgeable. In addition, those who score mean and above for attitude question were labeled as having favorable attitude. Regarding blood donation practice, having at least one history of blood donation was used to label them as having practice.

\section{Data processing and analysis}

All the questionnaires were checked visually, coded, and entered into EPI info version 7.0, then transferred to SPSS version 20 for analysis. Frequencies and proportions were used for descriptive analysis. Binary logistic regression analysis was used to examine association between the explanatory variables and dependant variables. All variables with $p$ value $<0.2$ in bivariate logistic regression analysis were entered into the final multiple logistic regression model to identify variables independently associated with KAP towards blood donation. Backward stepwise likelihood ratio was used to select the final independent predictors. The significance of odds ratio (OR) was declared at $p$ value $<0.05$.

\section{Result}

Socio demographic and factors related with blood donation A total of 556 health professionals were participated in this study making response rate of $100 \%$. The mean age of study participants were $27.3 \pm$ S.D: 7.5. Majority 218 $(39.2 \%)$ of the participants were within the age category of 23-29 years and 303 (54.5\%) were female. Regarding to marital status and educational level, 293 (52.7\%) and $270(48.6 \%)$ were married and degree holders respectively. Of the 556 study participants, 522 (93.8\%) were orthodox; 295 (53.1\%) had work experience of less than 6 years; 147 (26.4) were served on outpatient department; $313(56.3 \%)$ were with nursing profession. The monthly salary of $277(49.8 \%)$ participant were 10003000 ETB and 446 (80.2\%) knew their HIV test status (Table 1). 
Table 1 Socio demographic and factors related with blood donation of health professionals in Tigray public hospitals north Ethiopia August-September $2016(n=556)$

\begin{tabular}{|c|c|c|}
\hline Variables & $\begin{array}{l}\text { Frequency } \\
(n=556)\end{array}$ & Percentage (\%) \\
\hline \multicolumn{3}{|l|}{ Age } \\
\hline$<22$ & 35 & 6.3 \\
\hline $23-29$ & 218 & 39.2 \\
\hline $30-35$ & 113 & 20.3 \\
\hline$>36$ & 190 & 34.2 \\
\hline \multicolumn{3}{|l|}{ Sex } \\
\hline Male & 253 & 45.5 \\
\hline Female & 303 & 54.5 \\
\hline \multicolumn{3}{|l|}{ Marital status } \\
\hline Married & 293 & 52.7 \\
\hline Single & 218 & 39.2 \\
\hline Divorced & 33 & 5.9 \\
\hline Widowed & 12 & 2.2 \\
\hline \multicolumn{3}{|l|}{ Educational status } \\
\hline Diploma & 253 & 45.5 \\
\hline Degree & 270 & 48.6 \\
\hline Masters and above & 20 & 3.6 \\
\hline Specialist & 9 & 1.6 \\
\hline Others & 4 & 0.7 \\
\hline \multicolumn{3}{|l|}{ Religion } \\
\hline Orthodox & 522 & 93.8 \\
\hline Muslim & 27 & 4.9 \\
\hline Others & 7 & 1.3 \\
\hline \multicolumn{3}{|l|}{ Service year (years) } \\
\hline $0-6$ & 295 & 53.1 \\
\hline $7-12$ & 66 & 11.9 \\
\hline$\geq 13$ & 195 & 35.1 \\
\hline \multicolumn{3}{|l|}{ Department } \\
\hline Inpatient & 122 & 21.9 \\
\hline Operation room & 60 & 10.8 \\
\hline Laboratory & 50 & 9 \\
\hline Out patient & 147 & 26.4 \\
\hline $\mathrm{MCH}$ & 80 & 14.4 \\
\hline Pharmacy & 42 & 7.6 \\
\hline Radiology & 17 & 3.1 \\
\hline Others & 38 & 6.8 \\
\hline \multicolumn{3}{|l|}{ Profession } \\
\hline Physician & 30 & 5.4 \\
\hline Nurse & 313 & 56.3 \\
\hline Laboratory & 55 & 9.9 \\
\hline Pharmacy & 34 & 6.1 \\
\hline Midwifery & 41 & 7.4 \\
\hline Others & 83 & 14.9 \\
\hline \multicolumn{3}{|l|}{ Monthly income } \\
\hline $1000-3000$ & 277 & 49.8 \\
\hline $3001-6000$ & 244 & 43.9 \\
\hline $6001-9000$ & 24 & 4.3 \\
\hline
\end{tabular}

Table 1 (continued)

\begin{tabular}{lcc}
\hline Variables & $\begin{array}{l}\text { Frequency } \\
(\mathbf{n = 5 5 6 )}\end{array}$ & Percentage (\%) \\
\hline $\begin{array}{l}\text { > } 9000 \\
\text { HIV test }\end{array}$ & 11 & 2 \\
Yes & 446 & 80.2 \\
No & 110 & 19.8 \\
Motivation to donate blood & & \\
Yes & 421 & 75.7 \\
No & 135 & 24.3 \\
Knowledge & & \\
Yes & 318 & 57.2 \\
No & 238 & 42.8 \\
Attitude & & \\
Yes & 243 & 43.7 \\
No & 313 & 56.3 \\
\hline
\end{tabular}

Study participants with adequate knowledge on blood donation was 318 (57.2\%) whereas 238 (42.8\%) were with inadequate knowledge. From the total participants 243 (43.7\%) have adequate attitude towards blood donation whereas $313(56.3 \%)$ have inadequate attitude variables (Table 1).

\section{Blood donation practice and associated factors among health professionals}

Regarding practice, from all participants 266 (47.8\%) have ever donated blood at least once in their life time but 290 (52.2\%) have never donate. Variables that are significantly associated in bivariable logistic regression analysis only with practice of blood donation were, service year, being motivated by another person to donate and had HIV test previously. In the multi variable logistic regression analysis age greater than 30 years, married health professionals, level of education, adequate knowledge and adequate attitude were found to be significantly associated with practice of blood donation. Those health professionals greater than 30 years old were 2.7 times more likely participated on blood donation practice than those aged $\leq 22$ years old (AOR $=2.75695 \%$ CI 1.055 7.197). Married health professionals were 1.7 times more participated on blood donation practice than those single health professionals ( $\mathrm{AOR}=1.72995 \% \mathrm{CI} 1.091-2.739$ ). Health professionals having degree in their education level were $69 \%$ less likely to participate on blood donation compared to the specialist $(\mathrm{AOR}=0.31595 \% \mathrm{CI}$ 0.104-0.950).

Participants having adequate knowledge on blood donation were 3.4 times more likely donate blood as compared to inadequate knowledge (AOR $=3.40395 \%$ CI 2.296-5.044). Health professionals having adequate 
attitude towards blood donation were 3.4 times more likely donated blood than the counter parts $(\mathrm{AOR}=3.41$ 95\% CI 2.320-5.041) (Table 2).

\section{Discussion}

This study has assessed blood donation practice and associated factors among health professionals in Tigray regional state public hospitals. Nearly half of the study participants $47.8 \%$ reported that they have ever donated blood at least once in their life time. This finding is higher than the finding of the study conducted in University of Gondar Hospital; Northwest Ethiopia which reported that blood donation practice among health professionals was 33.2\% [6]. A study in Debre Markos town, northwest Ethiopia also reported that $32.6 \%$ of health professionals have ever donated blood at least once in their life time [8]. It is also higher than similar studies conducted in Addis Ababa among health professionals of Tukur Anbessa hospital 38.3\% [7]. This difference could be due to repeated campaigns conducted in our study area by the regional health bureau and other blood bank centers in the region.

Age of health professionals 30 years or above was positively associated with blood donation practice. Those age 30 years or above were 2.76 times more likely to donate blood than those with age 22 years or below. Similar findings were also reported in other part of Ethiopia [6].

Table 2 Multivariable logistic regression analysis for factors associated with practice of blood donation among health professionals in Tigray public hospitals, north Ethiopia August-September $2016(n=556)$

\begin{tabular}{|c|c|c|c|c|}
\hline \multirow[t]{2}{*}{ Explanatory variables } & \multicolumn{2}{|c|}{ Ever donated blood } & \multirow[t]{2}{*}{ COR $(95 \% \mathrm{Cl})$} & \multirow[t]{2}{*}{ AOR $(95 \% \mathrm{Cl})$} \\
\hline & Yes & No & & \\
\hline \multicolumn{5}{|l|}{ Age } \\
\hline$\leq 22$ & $9(3.4 \%)$ & $26(9 \%)$ & 1 & \\
\hline $23-29$ & $86(32.3 \%)$ & $132(45.5 \%$ & $1.882(0.841,4.211)$ & $1.847(0.750,4.547)$ \\
\hline$\geq 30$ & $171(64.3 \%$ & $132(45.5 \%$ & $3.742(1.696,8.257)$ & $2.756(1.055,7.197)^{*}$ \\
\hline \multicolumn{5}{|l|}{ Marital status } \\
\hline Single & $78(29.3 \%)$ & $140(48.3 \%$ & 1 & \\
\hline Married & $159(59.8 \%$ & $134(46.2 \%$ & $2.130(1.486,3.052)$ & $1.729(1.091,2.739)^{*}$ \\
\hline Divorced & $20(7.5 \%)$ & $13(4.5 \%)$ & $2.761(1.303,5.853)$ & $1.644(0.679,3.985)$ \\
\hline Widowed & $9(3.4 \%)$ & $3(1 \%)$ & $5.385(1.416,20.47)$ & $2.402(0.549,10.505)$ \\
\hline \multicolumn{5}{|l|}{ Educational status } \\
\hline Specialist & $2(0.8 \%)$ & $7(2.4 \%)$ & 1 & \\
\hline Diploma & $132(49.6 \%$ & $121(41.7 \%$ & $1.284(0.911,1.811)$ & $0.950(0.626,1.443)$ \\
\hline Degree & $124(46.6 \%$ & $146(50.3 \%$ & $0.505(0.188,1.352)$ & $0.315(0.104,0.95)^{*}$ \\
\hline Masters and above & $6(2.3 \%)$ & $14(4.8 \%)$ & $0.336(0.069,1.649)$ & $0.370(0.070,1.954)$ \\
\hline Others & $2(0.7 \%)$ & $2(0.8 \%)$ & $1.177(0.163,8.481)$ & $1.127(0.116,10.926)$ \\
\hline \multicolumn{5}{|l|}{ Service year (years) } \\
\hline $0-6$ & $115(43.2 \%$ & $180(62.1 \%$ & 1 & \\
\hline $7-12$ & 29 (10.9\%) & $37(12.8 \%)$ & $1.227(0.715,2.104)$ & $1.124(0.575,2.198)$ \\
\hline$\geq 13$ & $122(45.9 \%$ & $73(25.1 \%)$ & $2.616(1.802,3.797)$ & $1.538(0.904,2.619)$ \\
\hline \multicolumn{5}{|l|}{ Motivation donate blood } \\
\hline No & $54(20.3 \%)$ & 81 (27.9\%) & 1 & \\
\hline Yes & $212(79.7 \%$ & $209(72.1 \%$ & $1.522(1.026,2.256)$ & $0.623(0.387,1.003)$ \\
\hline \multicolumn{5}{|l|}{ HIV test in the past } \\
\hline No & $225(84.6 \%$ & $221(76.2 \%$ & 1 & \\
\hline Yes & $41(15.4 \%)$ & $69(23.8 \%)$ & $0.58(0.380,0.896)$ & $0.665(0.398,1.110)$ \\
\hline \multicolumn{5}{|l|}{ Knowledge } \\
\hline In adequate & $73(27.4 \%)$ & 165 (56.9\% & 1 & \\
\hline Adequate & $193(72.6 \%$ & $125(43.1 \%$ & $3.490(2.455,4.982)$ & $3.403(2.296,5.044)^{*}$ \\
\hline \multicolumn{5}{|l|}{ Attitude } \\
\hline In adequate & $108(40.6 \%$ & $205(70.7 \%$ & 1 & \\
\hline Adequate & $158(59.4 \%$ & 85 (29.3\%) & $3.528(2.482,5.016)$ & $3.419(2.320,5.041)^{*}$ \\
\hline
\end{tabular}

${ }^{*} p$ value $\leq 0.05$ considered as statistical significant 
The probable reason may be as their age increases their awareness to donate blood through time increases.

Married health professionals were 1.7 times more likely to donate than those who were single. This is contradicting with a study from Lagos Nigeria which reported willingness to donate blood was positively associated with being single was a significant predictor of blood donation [5]. This difference may be due to socio-demographic difference of the two populations.

In this study having higher level of formal education is significantly associated with blood donation practice. This is supported by the study from Debre Markos town, northwest Ethiopia which revealed that health professionals who attended certificate and above education were more likely to donate blood [5]. This may be due to the fact that having higher education is associated with exposing to frequent blood donation campaigns and blood donation related information to have better knowledge, attitude and then better blood donation practice.

Having adequate knowledge about blood donation is positively associated with blood donation practice. Health professionals who had adequate knowledge of blood donation were 3.4 times more likely to donate blood than those who had inadequate knowledge. This is supported by a study from Debre Markos, Northwest Ethiopia which reported that the practice of blood donation was higher among respondents who were knowledgeable [8]. Another study conducted in Gondar Hospital, Northwest Ethiopia also revealed that being knowledgeable is associated with blood donation practice [6]. That is also supported by studies done in Addis Ababa health facility health care workers in Ethiopia [7]. This justifies that having more knowledge about importance of blood donation makes health professionals to donate blood.

Health professionals having adequate attitude about blood donation were 3.4 times more likely to participate on blood donation than those having inadequate attitude. This is supported by the study from Debre Markos, Northwest Ethiopia which reported favorable attitude is significantly associated with blood donation practice [8]. The study from Gondar University hospital, Northwest Ethiopia also revealed that having favorable attitude is a predictor to blood donation practice [6]. This is supported by a study done in Addis Ababa health facility [26].

\section{Conclusion}

Nearly half of the health professionals included in the study reported they donated blood at least once in their life time. Age of health professionals 30 years or above, being married, having formal education, having adequate knowledge and having adequate attitude about blood donation were factors associated significantly with blood donation practice among health professionals in public health institutions of Tigray regional state in Ethiopia. So that, the Red Cross and Red Crescent Associations together with respective government ministries need to engage on promoting blood donation by designing different strategies that can improve knowledge and attitude of people about blood donation. The blood bank offices at different levels also need to conduct repeated blood donation campaigns at health institutions to encourage blood donation by health professionals.

\section{Limitation}

This study was conducted through cross-sectional study and may not show the cause and effect relationship.

\section{Abbreviations}

Cl: confidence interval; AOR: adjusted odd ratio; SPSS: Statistical Package for Social Sciences.

\section{Authors' contributions}

TT: conceived and designed the study, analyzed the data and wrote the manuscript. HG, TB, THA, BG, EH, TG involved in data analysis, drafting of the manuscript and advising the whole research paper. $\mathrm{HG}$ also were involved in the interpretation of the data and contributed to manuscript preparation. All authors read and approved the final manuscript.

\section{Author details}

${ }^{1}$ Aksum Blood Bank Branch Office, Tigray Regional Health Bureau, Aksum, Ethiopia. ${ }^{2}$ Department of Reproductive Health, School of Public Health, College of Health Sciences, Aksum University, Aksum, Ethiopia. ${ }^{3}$ Department of Human Nutrition, School of Public Health, College of Health Sciences, Aksum University, Aksum, Ethiopia. ${ }^{4}$ Departments of Medical Laboratory Technology, College of Health Sciences, Aksum University, Aksum, Ethiopia. ${ }^{5}$ Department of Neonatal Nursing, School of Nursing, College of Health Sciences, Aksum University, Po.Box 298, Aksum, Ethiopia.

\section{Acknowledgements}

We would like to thank all study participants and data collectors for their contribution in success of our work.

\section{Competing interests}

This manuscript maintains no competing financial interests declaration from any person or organization, or non-financial competing interests such as political, personal, religious, ideological, academic, intellectual, commercial or any other.

\section{Availability of data and materials}

The data sets used and analyzed during the current study available from the corresponding author on reasonable request.

\section{Consent to publish}

Not applicable.

\section{Ethics approval and consent to participate}

This study was reviewed and approved by the Ethical Review Committee of Aksum University, College of Health Sciences and Comprehensive Specialized Hospital. Permission letters were obtained from each hospital. Voluntary informed written consent was obtained from each study participants after explaining the purpose, aim, objectives and the benefits of the result of this study, and they can withdraw from the study at any time if they are not comfortable about the questionnaire. In order to keep confidentiality of any information provided by study subjects, the data collection procedure was anonymous. The study subjects were assured for the confidentiality of their responses no any secret idea behind it. 


\section{Funding}

There is no funding for this research. All cost of data collection and analysis were covered by the authors.

\section{Publisher's Note}

Springer Nature remains neutral with regard to jurisdictional claims in published maps and institutional affiliations.

\section{Received: 10 August 2018 Accepted: 20 September 2018} Published online: 24 September 2018

\section{References}

1. World Health Organization. Global database on blood safety, 2011. Geneva:WHO; 2011.

2. World Health Organization. Towards $100 \%$ voluntary blood donation: a global framework for action. Geneva: World Health Organization; 2010.

3. Bates I, Chapotera GK, McKew S, Den Van, Broek N. Maternal mortality in sub-Saharan Africa: the contribution of ineffective blood transfusion services. BJOG. 2008;115(11):1331-9.

4. World Health Organization. Universal access to safe blood transfusion. Geneva: World Health Organization; 2008.

5. Nwogoh B, Aigberadion U, Nwannadi Al. Knowledge, attitude, and practice of voluntary blood donation among healthcare workers at the University of Benin Teaching Hospital, Benin City, Nigeria. J Blood Transfus. 2013. https://doi.org/10.1155/2013/797830.

6. Arage $\mathrm{G}$, Ibrahim S, Adimasu E. Blood donation practice and its associated factors among health professionals of University of Gondar Hospital, Northwest Ethiopia: a cross sectional study. BMC Res Notes. 2017;10(1):294

7. Teklu S. Knowledge, attitude, practice and associated factors of blood donation among health care workers in Tikur Anbessa specialized hospital, Addis Ababa, Ethiopia. Department of Emergency Medicine, College of Health Sciences, Addis Ababa University; 2015.

8. Bantayehu D. Knowledge, attitude, and practice of voluntary blood donation and associated factors among health care providers in Addis Ababa health facilities. Ethiopia. Occup Med Health Aff. 2015. https://doi. org/10.4172/2329-6879.1000209.

9. Sekoni AO, Balogun MR, Odukoya OO, Inem V, Onigbogi OO. Blood donation practices and willingness to donate among residents of an urban slum in Lagos Nigeria. Niger Postgrad Med J. 2014;21(1):21-7.

10. The Ethiopian Red Cross Society (ERCS). The Ethiopian Red Cross Society annual report. 2014

11. Organization WH. (WHO) Report Cooperation Strategy 2012-2015 Ethiopia_data reported by WHO. 2013

12. Blood safety and availability WHO Fact sheet, Fact sheet No. 279. 2014

13. Federal democratic republic of Ethiopia, ministry of health. National blood transfusion. Services strategy. 2005.
14. WHO global data base. Blood safety. 2012.

15. Gidey G, Hailu B, Nigus K, Hailu T, Gerensea H. Timing of first focused antenatal care booking and associated factors among pregnant mothers who attend antenatal care in Central Zone, Tigray, Ethiopia. BMC Res Notes. 2017;10(1):608.

16. Kebede A, Molla B, Gerensea H. Assessment of risky sexual behavior and practice among Aksum University students, Shire Campus, Shire Town, Tigray, Ethiopia, 2017. BMC Res Notes. 2018;11:88. https://doi. org/10.1186/s13104-018-3199-7.

17. Gerensea H, Kebede A, Baraki Z, Berihu H, Zeru T, Birhane E, Hintsa S, Siyum H, Kahsay G, Gidey G, Teklay G. Consistency of integrated management of newborn and childhood illness (IMNCI) in Shire Governmental Health Institution in 2017. BMC Res Notes. 2018;11(1):476.

18. Gerensea $\mathrm{H}$, Teklay $\mathrm{H}$. Trend of hypertension morbidity and mortality in Tigray Region from 2011 to 2015, Tigray, Ethiopia. BMC Res Notes. 2018;11(1):375

19. Mariye T, Tasew H, Teklay G, Gerensea H, Daba W. Magnitude of diabetes self-care practice and associated factors among type two adult diabetic patients following at public Hospitals in central zone, Tigray Region, Ethiopia, 2017. BMC Res Notes. 2018;11(1):380.

20. Seid A, Gerensea H, Tarko S, Zenebe Y, Mezemir R. Prevalence and determinants of erectile dysfunction among diabetic patients attending in hospitals of central and northwestern zone of Tigray, northern Ethiopia: a cross-sectional study. BMC Endocr Disord. 2017;17(1):16.

21. Birhane E, Kidanu K, Kassa M, Gerezgiher D, Tsegay L, Weldu B, Kidane G, Gerensea H. Lifespan and associated factors of peripheral intravenous Cannula among infants admitted in public hospitals of Mekelle City, Tigray, Ethiopia, 2016. BMC Nurs. 2017;16(1):33

22. Baraki Z, Girmay F, Kidanu K, Gerensea H, Gezehgne D, Teklay H. A cross sectional study on nursing process implementation and associated factors among nurses working in selected hospitals of Central and Northwest zones, Tigray Region, Ethiopia. BMC Nurs. 2017;16(1):54.

23. Weldesamuel GT, Atalay HT, Zemichael TM, Gebre HG, Abraha DG, Amare AK, Gidey EB, Alemayoh TT. Colostrum avoidance and associated factors among mothers having children less than 2 years of age in Aksum town, Tigray, Ethiopia: a cross-sectional study 2017. BMC Res Notes. 2018;11(1):601.

24. Girmay A, Marye T, Haftu M, Brhanu T, Gerensea H. Patients expectation strongly associated with patients perception to nursing care: hospital based cross sectional study. BMC Res Notes. 2018;11(1):310.

25. Gebremedhin G, Tetemke D, Gebremedhin M, Kahsay G, Zelalem H, Syum $\mathrm{H}$, Gerensea $\mathrm{H}$. Factors associated with latrine utilization among model and non-model families in Laelai Maichew Woreda, Aksum, Tigray, Ethiopia: comparative community based study. BMC Res Notes. 2018;11(1):586.

26. Holdershaw J, Gendall P, Wright M. Factors influencing blood donation behaviour, 2003, University of Otago. 2003.

Ready to submit your research? Choose BMC and benefit from

- fast, convenient online submission

- thorough peer review by experienced researchers in your field

- rapid publication on acceptance

- support for research data, including large and complex data types

- gold Open Access which fosters wider collaboration and increased citations

- maximum visibility for your research: over $100 \mathrm{M}$ website views per year

At $\mathrm{BMC}$, research is always in progress.

Learn more biomedcentral.com/submissions 